\title{
Are Average Platelet Volume (MPV), Red Cell Distribution Width (RDW) and Platelet Distribution Width (PDW) Guiding Markers for Acute Appendicitis Treatment Options?
}

\author{
Erkan Dalbaşı ${ }^{1}$ and Omer Lutfi Akgül ${ }^{2}$ \\ ${ }^{1}$ Affiliation not available \\ ${ }^{2}$ Diyarbakir Il Saglik Mudurlugu
}

January 17, 2021

\begin{abstract}
Background: Acute appendicitis (AA) is the most common cause of surgery performed for acute abdomen. The standard treatment for AA patients has been appendectomy for more than a century. use of broad-spectrum antibiotics, the medical treatment option has come to the fore in the treatment of uncomplicated AA. Aim: Evaluate whether WBC, platelet count, MPV, PDW, RDW, and C-reactive protein (CRP) values of patients diagnosed with uncomplicated AA clinically, with laboratory tests and radiologically with abdominal CT could be a marker for choosing medical or surgical treatment. Material and Method: 519 patients aged between 20 and 65 years who were diagnosed with uncomplicated AA by abdominal CT in our centre between January 2016 and January 2019 were retrospectively analysed. . The presence of at least one of the criteria of $7 \mathrm{~mm}$ or more appendix diameter and oedema or fluid accumulation around the appendix was accepted as uncomplicated AA. After the diagnosis of AA, 223 patients were treated medically, while 296 patients underwent laparoscopic appendectomy. The first group included patients who were treated medically and the second group included patients who underwent laparoscopic appendectomy. Results: Group 2 patients had higher mean platelet count $(\mathrm{p}<.005)$ and RDW ( $\mathrm{p}=.003)$ values compared to Group 1 patients, while mean PDW $(\mathrm{p}<.001)$ values were lower compared to those of Group 1 patients. The differences between the mean WBC, CRP and MPV values of the groups were not statistically significant $(\mathrm{p}>0.05)$. Conclusions: The standard treatment for acute appendicitis is surgery. Recently, studies supporting antibiotic therapy have been conducted in patients diagnosed with AA. As a result, we think that PDW, RDW, and platelet values in patients diagnosed with uncomplicated AA may be a guide in choosing patients to be treated with surgery or antibiotics. Key Words: acute appendicitis, laparoscopic appendectomy, antibiotic therapy.
\end{abstract}

\section{INTRODUCTION}

Acute appendicitis (AA) is the most common cause of surgery performed for acute abdomen (1). While the lifetime risk of $\mathrm{AA}$ is $12 \%$ in men, it is around $23 \%$ in women, and it is most common in the second and fifth decades (2). Anamnesis and physical examination are the basic steps for the diagnosis of AA. Laboratory parameters, ultrasonography, and computed tomography (CT) are auxiliary methods in diagnosis (3). The standard treatment for AA patients has been appendectomy for more than a century to prevent severe complications such as perforation, intra-abdominal infection, and sepsis. Owing to the progress made in imaging methods over time and the widespread use of abdominal CT, it can be clearly understood whether appendicitis is complicated. In addition to this, with the use of broad-spectrum antibiotics, the medical treatment option has come to the fore in the treatment of uncomplicated AA (4). In the guideline published by the World Emergency Surgery Society in 2016, it was reported that patients who were diagnosed with uncomplicated AA but did not want to undergo surgery can be treated with antibiotics (5). Complete blood count $(\mathrm{CBC})$ is a widely used laboratory test in the diagnosis of AA in emergency services. White blood cell 
(WBC) and neutrophil levels are the earliest inflammatory markers during AA. However, its sensitivity and specificity are quite variable according to the duration of the symptoms and the cut off values used. Thus, studies have been conducted in which platelet distribution width (PDW), red cell distribution width (RDW), platelets count (PLT), and mean platelet volume (MPV) values in CBC can be used in the diagnosis of AA (6). Platelets play an important role in the inflammation process. Indexes such as MPV and PDW are related to platelet activation and morphology (7). MPV refers to the mean size of circulating platelets, and this mean size increases with inflammation. Due to the change in platelet shape during platelet activation, pseudopod formation occurs and the amount of PDW increases (8). RDW is a measure of the variability in size of red blood cells and increases in inflammatory events (9).

In this study, we aimed to evaluate whether WBC, platelet count, MPV, PDW, RDW, and C-reactive protein (CRP) values of patients diagnosed with uncomplicated AA clinically, with laboratory tests and radiologically with abdominal CT could be a marker for choosing medical or surgical treatment.

\section{MATERIAL AND METHOD}

519 patients aged between 20 and 65 years who were diagnosed with uncomplicated AA by abdominal CT in our centre between January 2016 and January 2019 were retrospectively analysed. Informed consent forms were signed by all patients. The presence of at least one of the criteria of $7 \mathrm{~mm}$ or more appendix diameter and oedema or fluid accumulation around the appendix was accepted as uncomplicated AA. Patients with abscess, perforation, widespread inflammation, and tumours as a result of CT, patients with chronic systemic disease, who did not undergo CT, who underwent appendectomy during antibiotic therapy, and patients who had complications during surgical or medical treatment were excluded from the study. All patients were administered cefuroxime axetil twice a day by intravenous route for two days. Ciprofloxacin $500 \mathrm{mg}$ and metronidazole $500 \mathrm{mg}$ were administered orally twice daily for ten days. After the diagnosis of AA, 223 patients were treated medically, while 296 patients underwent laparoscopic appendectomy (LA). Patients were divided into two groups. The first group included patients who were treated medically and the second group included patients who underwent laparoscopic appendectomy. Groups were compared in terms of age, gender, WBC, platelet count, MPV, PDW, RDW and serum CRP levels. Patients in the group treated with antibiotics were questioned whether they developed recurrent appendicitis after 12 months.

\section{Statistical Analysis}

Data were collected and entered into the software of Statistical Package for Social Science (SPSS) 20. Numbers and percentage values were given to show descriptive qualitative data while mean scores, standard deviations, ranges, and medians with interquartile ranges (IQR) were given to show descriptive quantitative data. Chi-square test was used to compare the groups related to qualitative data, while the two groups were compared in terms of quantitative data and parametric distribution by using independent t-test and in terms of the nonparametric distribution by using the Mann-Whitney test. The value of $\mathrm{P}<0.05$ was considered statistically significant.

\section{RESULTS}

A total of 519 patients diagnosed with uncomplicated AA were divided into two groups. Group 1 consisted of 223 patients treated medically. Group 2 included 296 patients who underwent laparoscopic appendectomy. $92(41.25 \%)$ of the 223 patients in Group 1 were female and $131(58.75 \%)$ were male. Mean age was 29.82 \pm 15.32 (20-57). In Group 2, 130 (43.91\%) of 296 patients were female and 166 (56.09\%) of them were male. The mean age of group 2 patients was $43.00 \pm 17.35$ (20-65). The difference between the two groups in terms of mean age was significant (.019). Group 2 patients had higher mean platelet count $(\mathrm{p}<.005)$ and RDW (p $=.003)$ values compared to Group 1 patients, while mean PDW $(\mathrm{p}<.001)$ values were lower compared to those of Group 1 patients. The differences between the mean WBC, CRP and MPV values of the groups were not statistically significant $(\mathrm{p}>0.05)$. The demographic characteristics and laboratory values of the groups are summarized in Table 1. Laboratory parameters with significant differences between groups are shown in Graphic 1. None of the patients treated with antibiotics had recurrent appendicitis after 12 months. 


\section{DISCUSSION}

Surgical method in the treatment of acute appendicitis still ranks first in the world. As with all surgical treatments, there may be early or late complications in appendectomy (10). Negative appendectomy rate is around $40 \%$, especially in fertile women (11). Conservative antibiotic therapy in the treatment of uncomplicated AA is an ongoing discussion in order to avoid negative appendectomy and postoperative complications. The main reason for the discussion is the lack of sufficient information about the long-term results of antibiotic treatment (12). Meta-analyses show that antibiotic treatment has similar rates to surgical treatment in terms of complications $(4,13,14,15)$. In the study conducted by Salminen et al., 273 patients diagnosed with acute appendicitis underwent appendectomy, while 257 patients received antibiotic treatment and the 5 -year follow-up results were evaluated. Complication rate was significantly higher in the surgical group. Appendectomy was performed in 85 patients from the antibiotic group due to recurrent appendicitis, and 7 of them were found to have negative appendectomy (4). In the study conducted by Di Saverio et al., 20.7\% $(25 / 121)$ of the patients who were treated conservatively during an average follow-up of 19 months required surgical treatment (16). Literature data indicate that antibiotic treatment should be discussed more seriously and effectively in the treatment of uncomplicated AA (17). In our study, we evaluated whether WBC, platelet count, MPV, PDW, RDW values in CBC and CRP are effective in distinguishing patients who will be treated with surgery or antibiotics in patients diagnosed with AA without complication with clinical, radiological and laboratory data and undergoing laparoscopic surgery and antibiotic treatment. CBC is a widely used, inexpensive and effective laboratory parameter in the diagnosis of AA.

In the study conducted by Ishizuka et al., and in a separate study by Boshnak et al, the mean age was found to be higher in patients diagnosed with complicated AA compared to the uncomplicated group $(6,17)$. These data were consistent with our study. In our study, the mean age of the LA group was higher than the medical treatment group.

The WBC value is the first to rise and the most commonly used laboratory parameter in the diagnosis of AA (18). In our study, the WBC value was high in both groups, but the difference between them was not statistically significant.

In the study conducted by Park et al., patients who were diagnosed with AA uncomplicated by CT were divided into two groups. While antibiotic treatment was given to one group, the other group was not given medical or surgical treatment. After 19 months of follow-up, $20 \%$ of the patients in the antibiotic group and $23 \%$ of the patients in the other group required surgical treatment (19). In our study, recurrent appendicitis was not observed in the group treated with antibiotics during the 12-month follow-up.

The studies conducted revealed the relationship between inflammation and platelet value. During the inflammation process, the number of platelets decreases, especially in septic conditions (20). Platelet size correlates with activity; large platelets are young and active (21). In the study conducted by Boşnak et al., the mean platelet value was found to be statistically significant between uncomplicated AA and complicated AA groups (6). In the present study, the platelet value was found to be higher in the LAA group compared to the medical treatment group.

MVP is the mean size of platelets in the blood and is calculated by dividing thrombocytocrites by the number of platelets (22). Different results have been obtained in studies on the correlation between MVP and AA. In the studies performed by Saxena et al. and also Ceylan et al., MPV value was found to be low in patients diagnosed with AA $(23,24)$. In some studies, it was found higher compared to those of the control group (25). In the study conducted by Fan et al., no relationship was found between MVP and AA (26). In our study, there was no significant difference between the surgical group and the medically treated group.

PDW is the measure of the width of the platelet size distribution. Studies have shown that PDW is associated with many diseases. In the study conducted by Yang et al., PDW value was found to be higher in severe preeclampsia compared to mild preeclampsia (27). In the study conducted by Albayrak et al., PDW value was found to be higher in AA patients compared to the control group (28). In the study conducted by Fan et al. PDW value was found to be higher in gangrenous appendicitis compared to the control group (26). In 
the study conducted by Bosnak et al., PDW value was found to be associated with AA (6). In our study, PDW value was found to be higher in the LA group than the medical treatment group.

RDW is used in the differential diagnosis of the cause of anaemia. It indicates the heterogeneity of red blood cells. In inflammatory conditions such as inflammatory bowel diseases, acute pancreatitis and sepsis, an increase in RDW values can be observed. Studies have shown that there is a relationship between RDW and inflammatory markers CRP, erythrocyte sedimentation rate and interleukin-6. Circulating inflammatory mediators suppress erythrocyte maturation. Therefore, larger reticulocytes entering the circulation lead to an increase in RDW (29). In the study conducted by Narc1 et al., RDW value was found to be significantly lower in patients with AA diagnosis compared to the control group. They stated that RDW was higher in chronic inflammations rather than acute inflammation (30). In the study conducted by Bosnak et al., RDW value was found to be higher in the complicated AA group compared to the non-complicated group (6). In our study, the RDW value of the group treated with LAA was found to be higher than the group treated with antibiotics.

The C-reactive protein is an acute phase reactant. Its value increases in correlation with the severity of inflammation (31). Studies have found that CRP has a high sensitivity in the diagnosis of AA (32). These findings are compatible with our study. In the present study, the CRP value was found to be high in patients with AA, but there was no difference between the surgery group and the medical group.

\section{CONCLUSION}

The standard treatment for acute appendicitis is surgery. AA constitutes a significant part of emergency surgeries performed for acute abdomen worldwide. AA surgery is performed laparoscopically in many centres today. Recently, studies supporting antibiotic therapy have been conducted in patients diagnosed with AA. In these studies, it was observed that surgical treatment was more expensive and caused more labour loss. Meta-analyses show that the non-surgical method is successful. In the light of these data, we studied whether the laboratory parameters used in the diagnosis of AA are markers in order to determine whether the surgical or antibiotic treatment options will be applied to patients with a diagnosis of uncomplicated AA. As a result, we think that PDW, RDW, and platelet values in patients diagnosed with uncomplicated AA may be a guide in choosing patients to be treated with surgery or antibiotics. However, multi-centred prospective studies with higher number of cases are needed to have an idea about this issue.

\section{LIMITATION}

One of the limiting factors in our study is the short follow-up period in terms of recurrence of patients who were discharged after being treated with antibiotherapy. It can be said that another limitation is that although there are studies on AA medical treatment in the literature, there are few comparisons to distinguish between antibiotic treatment and surgical treatment options.

\section{REFERENCES}

1. Andersson RE. Meta-analysis of the clinical and laboratory diagnosis of appendicitis. Br J Surg. 2004;91:28-37.

2. Addiss DG, Shaffer N, Fowler BS, Tauxe RV. The epidemiology of appendicitis and appendectomy in the United States. Am J Epidemiol. 1990;132(5):910-925.

3. Livingston E, Vons C. Treating appendicitis without surgery. JAMA. 2015;313(23):2327-2328.

4. Salminen P, Tuominen R, Paajanen H, Rautio T, Nordström P, Aarnio M et al. Five-Year Follow-up of Antibiotic Therapy for Uncomplicated Acute Appendicitis in the APPAC Randomized Clinical Trial JAMA. 2018 Sep 25;320(12):1259-1265.

5. Di Saverio S, Birindelli A, Kelly MD, Coccolini F, Ansaloni L, van Ramshorst GH, Campanelli G, Khokha V, Moore EE, Peitzman A, et al. WSES Jerusalem guidelines for diagnosis and treatment of acute appendicitis. World J Emerg Surg. 2016;11:34. 
6. Boshnak N, Mohamed Boshnaq M , Hatem Elgohary. Evaluation of Platelet Indices and Red Cell Distribution Width as New Biomarkers for the Diagnosis of Acute Appendicitis J Invest Surg. 2018 Apr;31(2):121-129.

7. Thachil J. Platelets in inflammatory disorders: a pathophysiological and clinical perspective. Semin Thromb Hemost. 2015;41:572-581.

8. Aydogan A, Akkucuk S, Arica S, et al. The analysis of mean platelet volume and platelet distribution width levels in appendicitis. Indian J Surg. 2015;77:495-500.

9. Dinc T, Senol K, Yildiz B, et al. Association between red cell distribution width and mean platelet volume with appendicitis: a myth or a fact. Bratisl Lek Listy. 2015;116:499-501.

10. Jones K, Penn AA, Dunn EL, et al. Are negative appendectomies still acceptable? Am J Surg. 2004;188:748-754.

11. Flum DR, Koepsell T. The clinical and economic correlates of misdiagnosed appendicitis. Arch Surg. 2002;137:799-804.

12. Talan A.D, Saltzman D.J, DeUgarte D.A, Moran J.G. Methods of conservative antibiotic treatment of acute uncomplicated appendicitis: A systematic review. J Trauma Acute Care Surg. 2019 Apr;86(4):722-736.

13. Harnoss JC, Zelienka I, Probst P, Grummich K, Müller-Lantzsch C, Harnoss JM, Ulrich A, Büchler MW, Diener MK. Antibiotics versus surgical therapy for uncomplicated appendicitis: systematic review and meta-analysis of controlled trials.Ann Surg. 2017(5);265:889-900.

14. Rollins KE, Varadhan KK, Neal KR, Lobo DN. Antibiotics versus appendicectomy for the treatment of uncomplicated acute appendicitis: an updated meta-analysis of randomised controlled trials. World J Surg. 2016;40(10):2305-2318.

15. Sakran JV, Mylonas KS, Gryparis A, Stawicki SP, Burns CJ, Matar MM, Economopoulos KP. Operation versus antibiotics-The "appendicitis conundrum" continues: A meta-analysis. J Trauma Acute Care Surg. 2017;82(6):1129-1137.

16. Di Saverio S, Sibilio A, Giorgini E, et al. The NOTA study (Non Operative Treatment for Acute Appendicitis): prospective study on the efficacy and safety of antibiotics (amoxicillin and clavulanic acid) for treating patients with right lower quadrant abdominal pain and long-term follow-up of conservatively treated suspected appendicitis. Ann Surg. 2014;260(1):109-117.

17. Ishizuka M, Shimizu T, Kubota K. Neutrophil-tolymphocyte ratio has a close association with gangrenous appendicitis in patients undergoing appendectomy. Int Surg. 2012;97:299-304.

18. Birchley D. Patients with clinical acute appendicitis should have pre-operative full blood count and C-reactive protein assays. Ann R Coll Surg Engl. 2006;88:27-32.

19. Park HC, Kim MJ, Lee BH. Randomized clinical trial of antibiotic therapy for uncomplicated appendicitis. Br J Surg. 2017;104(13):1785-1790.

20. Thachil J. Platelets in inflammatory disorders: a pathophysiological and clinical perspective. Semin Thromb Hemost. 2015;41:572-581.

21. Vagdatli E, Gounari E, Lazaridou E, et al. Platelet distribution width: a simple, practical and specific marker of activation of coagulation. Hippokratia 2010;14:28-32.

22. Briggs C, Harrison P, Machin SJ. Continuing developments with the automated platelet count. Int J Lab Hematol. 2007;29:77-91.

23. Ceylan B, Aslan T, Cinar A, et al. Can platelet indices be used as predictors of complication in subjects with appendicitis? Wien Klin Wochenschr. 2016 Dec;128(Suppl 8):620-625. 
24. Saxena D, Tandon M, Gedam B. Role of mean platelet volüme (MPV) in diagnosis of acute appendicitis. Int J Biomed Res. 2015;6:235-237.

25. Aktimur R, Cetinkunar S, Yildirim K, et al. Mean platelet volume is a significant biomarker in the differential diagnosis of acute appendicitis. Inf Cell Sig. 2015;2:e930.

26. Fan Z, Pan J, Zhang Y, et al. Mean platelet volüme and platelet distribution width as markers in the diagnosis of acute gangrenous appendicitis. Dis Markers. 2015;2015:542013.

27. Yang SW, Cho SH, Kwon HS, et al. Significance of the platelet distribution width as a severity marker for the development of preeclampsia. Eur J Obstet Gynecol Reprod Biol. 2014;175:107-111.

28. Albayrak Y, Albayrak A, Albayrak F, et al. Mean platelet volume: a new predictor in confirming acute appendicitis diagnosis. Clin Appl Thromb Hemost. 2011;17:362-366.

29. Sadaka F, O'Brien J, Prakash S. Red cell distribution width and outcome in patients with septic shock. J Intensive Care Med. 2013;28:307-313.

30. Narci H, Turk E, Karagulle E, et al. The role of red cell distribution width in the diagnosis of acute appendicitis: a retrospective case-controlled study. World J Emerg Surg. 2013;8:46-52.

31. Dalbaşı E, Gedik E, Tüzün A, Deniz Obay B. Correlation of Malondialdehyde and Antioxidant Enzyme Levels with Peritonitis Severity in Patients with Generalized Peritonitis. Dicle Med J (2020) 47 (2) : 293-303.

32. Yu Cw, Juan LI,Wu MH, et al. Systematic review and metaanalysis of the diagnostic accuracy of procalcitonin, C reactive protein and white blood cell count for suspected acute appendicitis. Br J Surg. 2013;100:322-329. 